\begin{tabular}{|cc|}
\hline VEHICLES & PASSENGERS \\
AUTOMOBILE & TRAIN \\
GÖTEBORG & SWEDEN \\
BENZENE & ARENES \\
SAMPLING & CHROMATOGRAPHY \\
\hline
\end{tabular}

Open access submitted manuscript version of Sci. Total Environ. 108 (1991) 225-233 Original report in Swedish

\title{
Exposure of commuters to volatile aromatic hydrocarbons from petrol exhaust
}

Lars Löfgren, Karin Persson, Ann-Margret Strömvall and Göran Petersson Department of Chemical Environmental Science, Chalmers University of Technology, S-41296 Göteborg (Sweden)

Early studies were made on exposure in taxis, buses and trams in urban traffic (Swedish report). A subsequent publication compares exposure to an extended range of light hydrocarbons in commuter buses and trains. 
EXPOSURE OF COMMUTERS TO VOLATILE AROMATIC HYDROCARBONS OF PETROL EXHAUST

Lars Löfgren, Karin Persson, Ann-Margret Strömvall and Göran Petersson

Department of Chemical Environmental Science

Chalmers University of Technology, S-412 96 Göteborg (Sweden)

\begin{abstract}
Twenty-two volatile aromatic hydrocarbons were determined in the air of an automobile coupé during commuting. Sampling was made on Tenax cartridges and laboratory determinations using thermal desorption combined with temperature-programmed capillary gas chromatography.

Selected hydrocarbons representative of petrol exhaust were assessed in an automobile and in an electric commuter train during eight parallel commuter trips. In the automobile coupé, the concentrations of benzene were $35-70 \mu \mathrm{g} / \mathrm{m}^{3}$ and of total aromatic hydrocarbons $200-400 \mu \mathrm{g} / \mathrm{m}^{3}$. The petrol exhaust levels were $5-10$ times higher in the automobile than in the commuter train compartment.
\end{abstract}




\section{INTRODUCTION}

In contrast to the large overall number of urban air pollutant studies, investigations related to commuting and road traffic are few, particularly for organic compounds. Recent reports give roadside data (Zweidinger et al., 1988) and emission data from road-driven light-duty vehicles (Bailey et al., 1990). The present study of exposure to hydrocarbons inside vehicles is based on previously developed analytical methods (Mattsson and Petersson, 1982). Some of the aromatic hydrocarbons reported have long been of concern with respect to health hazards as well as photo-oxidant formation and have been extensively studied in urban air (Singh et al., 1985). 


\section{EXPERIMENTAL}

\section{Commuter vehicles and lines}

Automobile samples were taken during driving in either direction on the main road (E3) between the central railway station of Göteborg and either Lerum or Alingsås, both northeast of Göteborg. The speed was normally kept near to the limits given in Fig. 1, which resulted in many passing cars. In the morning rush hour (especially $\left.07^{30}-08^{00}\right)$ slow queues $(0-4 \mathrm{~km})$ were formed for vehicles approaching Göteborg. The peak number of vehicles in the direction of Göteborg was about 3000 per hour.

Six reported trips were made by a new catalyst car and two trips by older cars. The cars were driven with warm engines from the start and with few stops during sampling. The fan was set at medium speed.

Parallel samples were taken in a compartment of commuter trains ( $\mathrm{ABB}$, model X10) between Göteborg, Lerum and Alingsås. The travelling time was approximately the same for train and automobile although the commuter train stopped at several intermediate stations. For about $10 \mathrm{~km}$ close to Göteborg the road runs near and partly within $100 \mathrm{~m}$ of the railway line. The commuter trains along the line take 7000 - 8000 one-way passengers per day. Smoking is not allowed in the trains. 


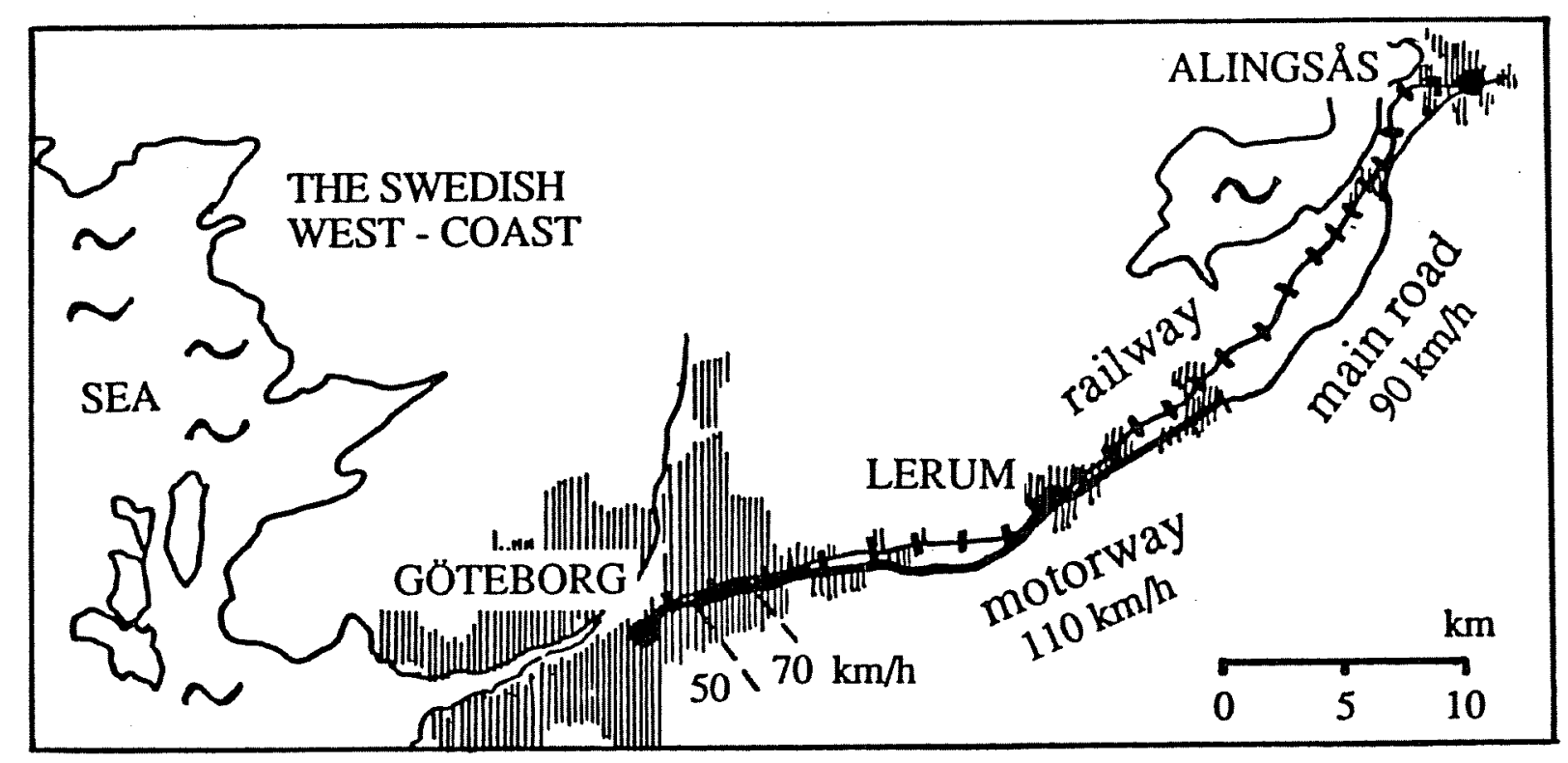

Fig. 1. Map showing the road and railway commuter lines. 
Sampling and analysis

Samples were taken on Tenax cartridges coupled to easily carried and handled high-precision air pumps. The cartridges were placed on the dash board in the automobile and on the rack in one of the commuter train compartments. Sampling was started simultaneously in the automobile and the train at departure and stopped on the arrival of automobile and train, respectively. The air volumes were in the range $0.20-2.0$ litres. Duplicate samples were taken and used to control the analytical quality.

The hydrocarbons were determined in the laboratory by thermal desorption combined with gas chromatography on a Carlo Erba instrument. The analytical column was a fused silica capillary $(25 \mathrm{~m} x$ $0.33 \mathrm{~mm}$ i.d.) with the cross-linked methyl-silicone BP-1 $(0.5 \mu \mathrm{m})$ as the stationary phase. The hydrocarbons were desorbed on to the cooled column and eluted by helium on raising the oven temperature $2^{\circ} \mathrm{C}$ per minute from $0{ }^{\circ} \mathrm{C}$. Detection was by flame ionization and retention times and quantitative data were obtained by a reporting integrator. The response factor of $n$-heptane was used throughout. Identifications of hydrocarbons were made from retention data and comparisons with known samples. The basic concepts applied were described in more detail in a previous paper (Mattsson and Petersson, 1982).

A complementary determination of $\mathrm{C}_{2}-\mathrm{C}_{6}$ hydrocarbons inside the automobile was made using a different analytical system based on an $\mathrm{Al}_{2} \mathrm{O}_{3}$ column (Berglund and Petersson, 1990). 


\section{RESULTS AND DISCUSSION}

\section{Volatile aromatic hydrocarbons}

The chromatogram of Fig. 2 and the corresponding data of Table 1 reflect the time-averaged exposure to 22 aromatic hydrocarbons during a representative automobile commuter trip.

The analytical separation of the hydrocarbons is illustrated by the chromatogram and by the retention data given. On the non-polar methylsilicone stationary phase, the $\mathrm{C}_{9}$ alkylbenzenes appear between the $\mathrm{C}_{9}$ and $\mathrm{C}_{10}$-alkanes and the tabulated $\mathrm{C}_{10}$ alkylbenzenes between the $\mathrm{C}_{10}$ and $\mathrm{C}_{11}$-alkanes. The prominent meta isomer is eluted just before the para isomer, whereas the corresponding ortho isomer is retained more strongly. An increasing number of alkyl groups on the benzene ring increases retention among isomeric alkylbenzenes. Indane and naphthalene are more strongly retained than the corresponding alkylbenzenes.

In the second column of Table 1, the percentual composition of the aromatic hydrocarbons is given. Toluene, benzene and $m$-xylene are the three most prominent species. All aromatic compounds exceeding $0.5 \%$ are included in the table. The composition was almost exactly the same in all automobile samples. A separate determination of all $\mathrm{C}_{2}$ and higher hydrocarbons in the automobile during commuting indicated that the aromatic hydrocarbons constituted $\sim 40 \%$ by weight of total hydrocarbons excluding methane. The last column of Table 1 gives the corresponding percentual composition.

The absolute concentrations of benzene, toluene and total aromatic 


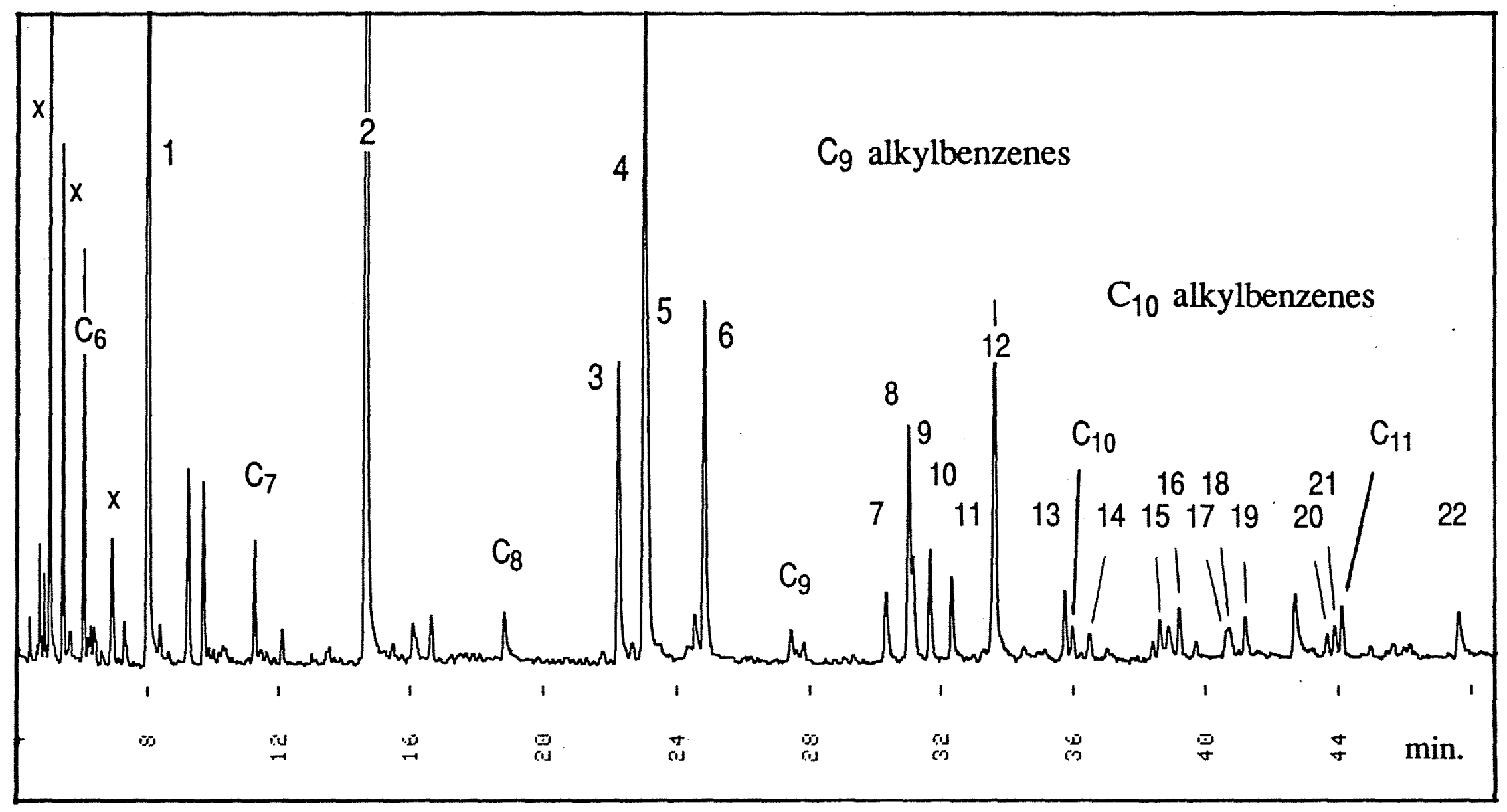

Fig. 2. Gas chromatographic separation of hydrocarbons sampled in an automobile coupé along the road commuter distance Lerum-Göteborg (the aromatic hydrocarbons are numbered from 1 to 22 according to Table 1 ; the $n$-alkanes $\mathrm{C}_{6}-\mathrm{C}_{11}$ and three isomeric hexanes $[\mathrm{x}]$ are marked). 
Table 1. Retention data and percentual composition of volatile aromatic hydrocarbons inside an automobile coupé on a main road with busy traffic.*

\begin{tabular}{|c|c|c|c|c|}
\hline & & Retention ${ }^{* *}$ & Concentratic & on ratios ${ }^{* * *}$ \\
\hline & & MU & $\%\left(\mathrm{CH}_{x, \text { ar }}\right)$ & $\%\left(\mathrm{CH}_{x}\right)$ \\
\hline 1 & Benzene $\quad\left(80.6 \mu \mathrm{g} / \mathrm{m}^{3}\right)$ & & 17 & 7.0 \\
\hline 2 & Methylbenzene (Toluene) & 7.44 & 30 & 11.8 \\
\hline 3 & Ethylbenzene & 8.40 & 5 & 2.2 \\
\hline 4 & 1,3-Dimethylbenzene ( $m$-Xylene) & 8.48 & 11 & 4.2 \\
\hline 5 & 1,4-Dimethylbenzene ( $p$-Xylene) & 8.49 & 6 & 2.4 \\
\hline 6 & 1,2-Dimethylbenzene (o-Xylene) & 8.70 & 7 & 2.7 \\
\hline 7 & Propylbenzene & 9.34 & 1 & 0.5 \\
\hline 8 & 1,3-Ethylmethylbenzene & 9.42 & 3 & 1.2 \\
\hline 9 & 1,4-Ethylmethylbenzene & 9.44 & 1 & 0.5 \\
\hline 10 & 1,3,5-Trimethylbenzene & 9.50 & 2 & 0.8 \\
\hline 11 & 1,2-Ethylmethylbenzene & 9.58 & 2 & 0.6 \\
\hline 12 & 1,2,4-Trimethylbenzene & 9.72 & 7 & 2.9 \\
\hline 13 & 1,2,3-Trimethylbenzene & 9.97 & 1 & 0.5 \\
\hline 14 & Indane & 10.06 & 0.5 & 0.2 \\
\hline 15 & 1,3-Methylpropylbenzene & 10.32 & 0.5 & 0.3 \\
\hline 16 & 1-Ethyl-3,5-dimethylbenzene & 10.40 & 1 & 0.4 \\
\hline 17 & 1-Ethyl-2,5-dimethylbenzene & 10.57 & 0.5 & 0.2 \\
\hline 18 & 1-Ethyl-2,4-dimethylbenzene & 10.58 & 0.5 & 0.2 \\
\hline 19 & 1-Ethyl-3,4-dimethylbenzene & 10.64 & 1 & 0.3 \\
\hline 20 & 1,2,4,5-Tetramethylbenzene & 10.94 & 0.5 & 0.2 \\
\hline 21 & 1,2,3,5-Tetramethylbenzene & 10.97 & 0.5 & 0.2 \\
\hline 22 & Naphthalene & 11.46 & 1 & 0.4 \\
\hline
\end{tabular}

* Lerum - Göteborg, May 19 1989, 0735-0757, weak winds, cloudy and $15^{\circ} \mathrm{C}$.

** Gas chromatographic retention times of alkylbenzenes in methylene units (MU), linearly interpolated between sequential alkanes ( $n$-heptane 7.00 etc.).

*** Given as $\%$ by weight of total aromatic hydrocarbons and as $\%$ by weight of total hydrocarbons excluding methane. 
hydrocarbons were 80,130 and $450 \mu \mathrm{g} / \mathrm{m}^{3}$ and correspond to the particularly high levels observed during the morning rush hour. Similar levels were observed in automobiles in urban street traffic, whereas much lowered concentrations were recorded at an increasing distance from traffic (Mattsson and Petersson, 1982). The concentrations recorded are typically five times higher than average urban levels (Singh et al., 1985) and urban exposure levels (Hartwell et al., 1987) reported for US cities. It is concluded that the high levels in automobiles are attributable mainly to the short distance to the exhaust pipes of the surrounding cars.

The composition of the alkylbenzenes largely reflects the composition of the petrol (Nelson et al., 1983). However, the proportion of benzene increases as compared with petrol because benzene is emitted not only unburnt but also, to a larger extent than alkylbenzenes, as a combustion product. The ratio of benzene to alkylbenzenes increases markedly with speed (Bailey et al., 1990). This explains the higher proportion of benzene in the commuter automobile as compared with the petrol-like composition in the the air of urban streets (Mattsson and Petersson, 1982). It should be observed that farther from the emissions, the proportion of benzene increases because alkylbenzenes are decomposed more rapidly, particularly in photochemically active air (Singh et al., 1985).

Specific petrol exhaust hydrocarbons

For a systematic study of the exposure of automobile and train commuters, the seven most abundant aromatic hydrocarbons were chosen together with $n$-hexane and three isomeric hexanes ( marked by $\mathrm{x}$ in Fig. 2). Results are given in Table 2 for these hydrocarbons. 
Table 2. Hydrocarbon determinations averaged over eight parallel commuter trips in automobile and train.

\begin{tabular}{|c|c|c|c|c|c|}
\hline \multirow{3}{*}{ 2-Methylpentane } & \multirow{2}{*}{$\begin{array}{c}\mathrm{Car} \\
\left(\mu \mathrm{g} / \mathrm{m}^{3}\right)\end{array}$} & \multirow{2}{*}{$\begin{array}{c}\text { Train } \\
\left(\mu \mathrm{g} / \mathrm{m}^{3}\right)\end{array}$} & \multirow{2}{*}{$\begin{array}{l}\text { Car/Train } \\
\text { ratio }\end{array}$} & \multicolumn{2}{|c|}{ Hydrocarbon ratios* } \\
\hline & & & & Car & Train \\
\hline & 17.9 & 2.7 & 6.6 & $2.2(0.4)$ & $2.5(0.4)$ \\
\hline 3-Methylpentane & 10.5 & 2.0 & 5 & $1.3(0.2)$ & $2.0(0.4)$ \\
\hline$n$-Hexane & 12.1 & 2.0 & 6.1 & $1.5(0.2)$ & $1.9(0.3)$ \\
\hline Methylcyclopentane & 5.0 & 0.8 & 6.3 & $0.6(0.1)$ & $0.8(0.1)$ \\
\hline Benzene & 57.1 & 6.6 & 8.7 & $7.0(0.5)$ & $6.1(0.4)$ \\
\hline Toluene & 99.9 & 12.3 & 8.1 & $12.1(0.5)$ & $11.3(0.9)$ \\
\hline Ethylbenzene & 17.9 & 2.1 & 8 & $2.2(0.1)$ & $2.1(0.4)$ \\
\hline$m, p$-Xylene & 58.9 & 7.5 & 7.9 & $7.1(0.4)$ & $7.1(0.4)$ \\
\hline$o$-Xylene & 23.0 & 2.9 & 7.9 & $2.8(0.1)$ & $2.8(0.4)$ \\
\hline 1,2,4-Trimethylbenzene & 25.1 & 3.3 & 7 & $3.1(0.3)$ & $3.3(0.9)$ \\
\hline
\end{tabular}

${ }^{*}$ Reflecting $\%$ by weight of total hydrocarbons (except methane), given that the tabulated hydrocarbons make up $40 \%$; standard deviations in parenthesis. 
Their portion of total hydrocarbons in the automobile is approximately the same $(\sim 40 \%)$ as that of total aromatic hydrocarbons. It is seen that the concentrations of all hydrocarbons determined were 5-10 times higher in the automobile than in the train.

Butanes and pentanes were excluded because they are prominent compounds of petrol vapour (Berglund and Petersson, 1990). Furthermore, they are not retained quantitatively on the adsorption cartridges under the conditions applied. The selected $\mathrm{C}_{6}$ and higher hydrocarbons in specific mutual concentrations are expected to be indicative of petrol exhaust. The similar hydrocarbon ratios and the low standard deviations in the train as well as the automobile strongly indicate petrol exhaust as the major source of hydrocarbons in both cases.

Low standard deviations for the train samples indicate a high reliability of the car-to-train ratios for the hydrocarbons. Bearing this in mind, the car-to-train ratio appears to be significantly higher for the alkylbenzenes than for the alkanes. This is probably related to the more efficient combustion of alkanes compared to alkylbenzenes (Nelson and Quigley, 1984) and to the more petrol-like composition of exhaust in urban housing areas compared to roads. It is concluded that the petrol exhaust in the train originates to an appreciable extent from urban traffic other than that of the main road. This is confirmed by the high car-to-train ratio for benzene which is explained by the higher proportion of benzene at high speeds (Bailey et al., 1990) and by a high exhaust-to-petrol ratio for benzene.

Petrol exhaust can be distinguished from most other sources of hydrocarbons by the different concentration ratios of the selected 
hydrocarbons. A study of the large solvent emissions from the Volvo automobile plant in Göteborg illustrates this point (Petersson, 1982). No influence from solvents or any hydrocarbon sources other than vehicle exhaust was detected in any of the commuter samples. Diesel exhaust could be traced by the $\mathrm{C}_{10}-\mathrm{C}_{12} n$-alkanes but contributes only to a small extent to benzene and even less to the other hydrocarbons selected to represent petrol exhaust.

Carbon monoxide and nitrogen oxides are frequently measured as exhaust indicators. Recent results from automobile coupés have been reported (Rudolf, 1990). The present method may be more complex but offers a higher specificity for petrol exhaust. Furthermore, it permits comparative exposure-related assessments of petrol exhaust at low concentrations such as those of the commuter train.

\section{Automobile compared with train}

In Table 3, comparative data for the commuter trips studied are given. Trips 2,5 and 6 were made during the morning traffic peak resulting in high concentrations. The high level and the high car-to-train ratio for trip 7 is probably explained by incidental stops in queues at traffic lights in Göteborg. The lower concentrations recorded for the complete line between Alingsås and Göteborg are explained by the lower traffic intensity farther away from Göteborg. It is concluded that the concentrations in the automobile are related primarily to the traffic flow on the road.

Leakages of evaporated petrol and petrol exhaust from the automobile itself may contribute significantly to coupé concentrations for vehicles with technical defects. The Saab 99 (1976) used for trip 2 may have leaked somewhat, whereas the results do not indicate a 
Table 3. Total concentrations of eleven prominent petrol exhaust hydrocarbons* during eight parallel commuter trips in automobile and train 1989.

\begin{tabular}{llll}
\hline Trip ** $^{*}$ & Car & Train & Car/Train \\
& $\left(\mu \mathrm{g} / \mathrm{m}^{3}\right)$ & $\left(\mu \mathrm{g} / \mathrm{m}^{3}\right)$ & ratio
\end{tabular}

1 L-G April $27 \quad 8^{05.825} \quad 5^{\circ} \mathrm{C}$, rainy, NNW $183 \quad 24 \quad 7.5$

2 L-G May $9 \quad 7^{40}-800 \quad 10^{\circ} \mathrm{C}$, cloudy, SW $590 \quad 66 \quad 9.0$

3 L-G May $11 \quad 7^{10.730} \quad 10^{\circ} \mathrm{C}$, sunny, W $251 \quad 42 \quad 6.0$

4 A-G May 12. $7^{20} 0_{-800} \quad 10^{\circ} \mathrm{C}$, rainy, ESE $202 \quad 28 \quad 7.3$

5 L-G May $16 \quad 7^{35.755} \quad 15^{\circ} \mathrm{C}$, cloudy, S $405 \quad 62 \quad 6.6$

6 L-G May $19 \quad 7^{35.755} \quad 15^{\circ} \mathrm{C}$, cloudy, S $408 \quad 58 \quad 7.0$

7 G-L May $19 \quad 16^{25-16^{45}} 20^{\circ} \mathrm{C}$, sunny, S $434 \quad 39 \quad 11.1$

$\begin{array}{llllll}8 \text { G-A May } 22 & 16^{20}-17^{00} & 25^{\circ} \mathrm{C} \text {, sunny, W } & 198 & 20 & 7.4\end{array}$

* Listed in Table 2. ${ }^{* *} G=$ Göteborg, L=Lerum, A=Alingsås. Weak and often fluctuating wind. 
contribution from leakage for trip 5 with a Volvo Amazon (1969). The other trips were made with a Nissan Micra (1988) with a three-way catalytic converter. Approximately $20 \%$ of the Swedish automobiles were equipped with catalytic converters by the time of the study.

The apparent independence of the concentrations in the train in relation to wind directions is explained by the previously discussed contributions of urban traffic other than those from the main road. Surrounding urban areas prevail between Göteborg and Lerum, while they are fewer between Lerum and Alingsås, as is reflected in the results. Trip 3 was made after an early morning inversion with elevated concentrations of pollutants at ground level which may explain the low car-to-train ratio. The higher urban pollutant levels in the winter season (Hartwell et al., 1987) may increase the concentrations in both automobile and train and may lower the car-to-train ratio somewhat as compared with the spring results given. On the other hand, lower concentrations are to be expected for most other commuter trains which tend to run farther from main roads and intensive urban traffic.

From the large car-to-train concentration ratio of about 7 , it is evident that health hazards from exposure to petrol exhaust during commuting are of particular interest to the motorists. Typical concentrations in the automobile of benzene, total aromatic hydrocarbons and total hydrocarbons except methane were 35-70, $200-400$ and $500-1000 \mu \mathrm{g} / \mathrm{m}^{3}$. The carcinogenic benzene is of special concern among the hydrocarbons. It should be observed that the proportion of benzene is particularly high inside road commuter automobiles. This may also be true for nitrogen dioxide (Rudolf, 1990). The long exposure time is unfavourable to commuters as 
compared with urban motorists and pedestrians occasionally exposed to high levels of petrol exhaust. The results indicate that commuting motorists may well receive half their daily dose during commuting.

Apparently, the commuter train is a superior alternative not only with respect to emissions but also with respect to the commuter's exposure to hazardous exhaust. The commuter train alternative can be promoted not only by new commuter lines and by improving train traffic, but also by offering park-and-ride systems at the commuter train stations. Information to commuting motorists on their personal exposure is likely to increase demands for the better alternative.

\section{ACKNOWLEDGEMENTS}

Financial support was obtained from the Swedish Transport Research Board. 


\section{REFERENCES}

Bailey, J.C., K. Gunary, B. Schmidt and M.L. Williams, 1990. Speciated hydrocarbon emissions from a sample of UK vehicles on the road over a range of speeds. Sci. Total Environ. 93: 199 - 206.

Berglund, P.M. and G. Petersson, 1990. Hazardous petro1 hydrocarbons from refuelling with and without petrol recovery. Sci. Total Environ. 91: 49 - 57.

Hartwell, T.D., E.D. Pellizzari, R.L. Perrit, R.W. Whitmore, H.S. Zelon and L. Wallace, 1987. Comparison of volatile organic levels between sites and seasons for the total assessment methodology (TEAM) study. Atmos. Environ. 21: 2413 - 2424.

Mattsson, M. and G. Petersson, 1982. Trace analysis of hydrocarbons in air using standard gas chromatographic and personal sampling equipment. Intern. J. Environ. Anal. Chem. 11: 211 - 219.

Nelson, P.F., S.M. Quigley and M.Y. Smith, 1983. Sources of atmospheric hydrocarbons in Sydney: A quantitative determination using a source reconciliation technique. Atmos. Environ. 17: 439 449.

Nelson, P.F. and S.M. Quigley, 1984. The hydrocarbon composition of exhaust emitted from gasoline fuelled vehicles. Atmos. Environ. 18: 79 - 87. 
Petersson, G., 1982. Ambient hydrocarbons from motor-car assembly plants in Scandinavia. Environ. Pollut. Ser. B. 4: 207 217.

Rudolf, W., 1990. Concentrations of air pollutants inside and outside cars driving on highways. Sci. Total Environ. 93: 263 - 276.

Singh, H.B., L.S. Solas, B.K. Contrell and R.M. Redmond, 1985. Distibution of aromatic hydrocarbons in the ambient air. Atmos. Environ. 19: 1911 - 1919.

Zweidinger, R.B., J.E. Sigsby, Jr., S.B. Tejada, F.D. Stump, D.L. Dropkin, W.D. Ray and J.W. Duncan, 1988. Detailed hydrocarbon and aldehyde mobile source emissions from roadway studies. Environ. Sci. Technol. 22: 956 - 962. 